\title{
Influence of Gender in Advanced Heart Failure Therapies and Outcome Following Transplantation
}

\section{OPEN ACCESS}

Edited by:

Chris J. Pemberton, University of Otago, New Zealand

Reviewed by:

Peter Ruygrok, Auckland District Health Board, New Zealand

Kristen M. Tecson, Baylor Scott \& White Research Institute (BSWRI), United States

${ }^{*}$ Correspondence: María Dolores García-Cosío mariadolores.garcia-cosio@ salud.madrid.org

Specialty section:

This article was submitted to Heart Failure and Transplantation,

a section of the journal

Frontiers in Cardiovascular Medicine

Received: 16 November 2020 Accepted: 12 January 2021 Published: 25 February 2021

Citation: García-Cosío MD, González-Vilchez F López-Vilella R, Barge-Caballero E, Gómez Bueno M, Martínez-Selles M, María Arizón J, Rangel Sousa $D$ González-Costello J, Mirabet $S$, Pérez-Villa F, Molina BD, Rábago G, Portolés Ocampo A, de la Fuente Galán L, Garrido I and Delgado JF (2021) Influence of Gender in Advanced Heart Failure Therapies and Outcome Following Transplantation Front. Cardiovasc. Med. 8:630113. doi: 10.3389/fCVm.2021.630113

\begin{abstract}
María Dolores García-Cosío ${ }^{1,2 *}$, Francisco González-Vilchez ${ }^{3}$, Raquel López-Vilella ${ }^{4}$, Eduardo Barge-Caballero ${ }^{2,5}$, Manuel Gómez Bueno ${ }^{2,6}$, Manuel Martínez-Selles ${ }^{2,7}$, Jose María Arizón ${ }^{8}$, Diego Rangel Sousa ${ }^{9}$, José González-Costello ${ }^{10}$, Sonia Mirabet ${ }^{11}$, Félix Pérez-Villa ${ }^{12}$, Beatriz Díaz Molina ${ }^{13}$, Gregorio Rábago ${ }^{14}$, Ana Portolés Ocampo ${ }^{15}$, Luis de la Fuente Galán ${ }^{16}$, Iris Garrido ${ }^{17}$ and Juan F. Delgado ${ }^{1,2,18}$
\end{abstract}

' Servicio de Cardiología, Hospital 12 de Octubre Madrid, Instituto de Investigación Sanitaria Hospital 12 de Octubre (imas12), Madrid, Spain, ${ }^{2}$ Centro de Investigación Biomédica en Red Cardiovascular (CIBERCV), Madrid, Spain, ${ }^{3}$ Servicio de Cardiología, Hospital Universitario Marqués de Valdecilla, Santander, Spain, ${ }^{4}$ Servicio de Cardiología, Hospital Universitari i Politecnic La Fe, Valencia, Spain, ${ }^{5}$ Servicio de Cardiología, Complejo Hospitalario Universitario de A Coruña, A Coruña, Spain, ${ }^{6}$ Servicio de Cardiología, Hospital Universitario Puerta de Hierro Majadahonda, Madrid, Spain, ${ }^{7}$ Servicio de Cardiología, Hospital General Universitario Gregorio Marañón, Universidad Europea, Universidad Complutense, Madrid, Spain, ${ }^{8}$ Servicio de Cardiología, Hospital Universitario Reina Sofía, Cordoba, Spain, ${ }^{9}$ Servicio de Cardiología, Hospital Universitario Virgen Del Rocío, Seville, Spain, ${ }^{10}$ Servicio de Cardiología, Hospital Universitari De Bellvitge, Hospitalet de Llobregat, Spain, ${ }^{11}$ Servicio de Cardiología, Hospital Santa Creu i Sant Pau, Barcelona, Spain, ${ }^{12}$ Servicio de Cardiología, Hospital Clínic i Provincial, Barcelona, Spain, ${ }^{13}$ Servicio de Cardiología, Hospital Universitario Central De Asturias, Oviedo, Spain, ${ }^{14}$ Servicio de Cirugía Cardiaca, Clínica Universidad De Navarra, Navarra, Spain, ${ }^{15}$ Servicio de Cardiología, Hospital Universitario Miguel Servet, Zaragoza, Spain, ${ }^{16}$ Servicio de Cardiología, Hospital Clínico Universitario De Valladolid, Valladolid, Spain, ${ }^{17}$ Servicio de Cardiología, Hospital Universitario Virgen De La Arrixaca, Murcia, Spain, ${ }^{18}$ Departamento de Medicina, Universidad Complutense de Madrid, Madrid, Spain

Biological differences between males and females change the course of different diseases and affect therapeutic measures' responses. Heart failure is not an exception to these differences. Women account for a minority of patients on the waiting list for heart transplantation or other advanced heart failure therapies. The reason for this underrepresentation is unknown. Men have a worse cardiovascular risk profile and suffer more often from ischemic heart disease. Conversely, transplanted women are younger and more frequently have non-ischemic cardiac disorders. Women's poorer survival on the waiting list for heart transplantation has been previously described, but this trend has been corrected in recent years. The use of ventricular assist devices in women is progressively increasing, with comparable results than in men. The indication rate for a heart transplant in women (number of women on the waiting list for millions of habitants) has remained unchanged over the past 25 years. Long-term results of heart transplants are equal for both men and women. We have analyzed the data of a national registry of heart transplant patients to look for possible future directions for a more in-depth study of sex differences in this area. We have analyzed 1-year outcomes of heart transplant recipients. We found similar results in men and women and no sex-related interactions with any of the factors related to survival or differences in death causes between men and women. We should keep trying to approach sex differences in prospective studies to confirm if they deserve a different approach, which is not supported by current evidence.

Keywords: gender, female, heart transplantation, outcome, women, advanced heart failure, ventricular assist device 


\section{INTRODUCTION}

There is a growing interest in sex-related differences in several clinical scenarios. Men and women differ in body composition and physiology; they present differences in pharmacokinetics and pharmacodynamics; and they may also respond differently to cardiovascular drugs. Women are underrepresented in most clinical trials, and real-life data have shown that they are less often treated with evidence-based therapies and experience adverse drug reactions more often (1). The reason for these differences between men and women is beyond the scope of the present study. Still, a better knowledge of these sex-related differences may be helpful to improve patient care.

Most heart failure (HF) patients are female. Women have a different clinical profile than men (2); they develop endstage HF at an older age, have a higher prevalence of HF with preserved ejection fraction and a lower prevalence of ischemic heart disease (IHD) (3-5). HF prognosis seems to be better in women with a lower rate of premature death than men (4). Moreover, in HF with reduced ejection fraction, women seem to have a better response to treatment, with a more favorable reverse remodeling regardless of the cause and severity of the left ventricle systolic dysfunction (5). In the field of advanced $\mathrm{HF}$, the underrepresentation of women among heart transplant (HT) or ventricular assist devices (VAD) recipients has been attributed to selection and referral bias and potentially poorer outcomes for these therapies. However, whether the described better outcomes in women with HF may also explain this under-representation in advanced heart failure stages has not been explored.

The majority of the studies in the field of heart transplantation (HT) are focused on donor-recipient mismatch (6-8). However, sex-related differences in patients on the waiting list for an HT or ventricular assist device and long term survival after an HT have been addressed recently. We aim to review those topics and look for sex-related differences in 1-year outcomes after an HT in an extensive nationwide registry to elucidate possible gaps that may need further investigation in the future.

\section{MATERIALS AND METHODS}

\section{Data Source}

The Spanish Heart Transplant Registry is a prospective database promoted by the Heart Failure Working Group of the Spanish Society of Cardiology, containing detailed clinical information about all HT procedures performed in our country from 1984 to the present. The registry is updated yearly with data supplied by all transplant centers in the country (9). The Ethics Committees of all participating centers have approved the Spanish Heart Transplantation Registry for investigational purposes.

For the present study, we included all patients aged $\geq 18$ years who underwent an HT in Spain from January 1, 2005 to December 31, 2019. Vital status at the end of followup and cause of death (when applicable) was known for all participants. The cause of death was locally adjudicated in each

Abbreviations: DCM, Dilated cardiomyopathy; HF, Heart Failure; HT, Heart transplant; IHD, ischemic heart disease; VAD, Ventricular assist device. participating center. We excluded recipients of a second HT and multiorgan recipients.

\section{Missing Data}

Missing data (Supplementary Table 1) were handled by multiple imputations using the wholly conditional specification method, generating 10 imputed datasets using all applicable adjustment variables and the outcome variable as predictors. The average of the 10 imputed data sets was used for analysis. For imputation, categorical and continuous variables were modeled using logistic regression and linear regression, respectively.

\section{Statistical Analysis}

Quantitative variables were summarized as median (interquartile range), and the Mann-Whitney $U$-test assessed betweensex differences. Categorical variables were summarized as percentages, with Chi-squared or Fisher's exact tests, as appropriate, for between-sex comparisons.

The primary outcome was 1-year all-cause mortality or re-transplantation. The associations between baseline population characteristics and outcome were fitted by the use of Cox proportional hazards regression. Multivariable adjustment included the recipient's sex and those variables with a significance level $<0.10$ in the univariable analysis. To further explore possible differences between men and women, additional multivariable models were considered to include the interaction between the recipient sex and each variable that reached statistical significance in the final multivariable analysis.

All statistical tests were 2-sided, and a $p$-value $<0.05$ was considered significant. All analyses were performed using the SPSS 25.0 (SPSS Inc., Chicago, IL).

\section{RESULTS}

A total of 3,616 HT procedures were performed in $16 \mathrm{HT}$ centers during the study period. We identified 869 female recipients $(24 \%)$. Sex-stratified baseline characteristics of the study population are shown in Table 1.

Women were significantly younger, and had a lower body mass index and predicted heart mass than men. They also presented with history of neoplastic disease more often.

Men had a poorer cardiovascular risk profile assessed as a higher prevalence of hypertension and diabetes, and triple the prevalence of peripheral artery disease. They also had two times the prevalence of chronic obstructive pulmonary disease. Men had undergone previous cardiac surgery more frequently than women.

HT indication was mainly due to IHD in men. Conversely, in women, HT's leading cause was dilated cardiomyopathy (DCM), followed by other etiologies (valvular heart disease, congenital heart disease, hypertrophic cardiomyopathy, restrictive cardiomyopathy, and myocarditis).

Urgent HT and mechanical circulatory support (VAD and intra-aortic balloon pump) were more frequent in men. Abnormal bilirubin levels and active infection at the moment of HT were also more frequent in men. 
TABLE 1 | Characteristics of the study cohort stratified by gender.

\begin{tabular}{|c|c|c|c|}
\hline & $\begin{array}{l}\text { Female } \\
(n=869)\end{array}$ & $\begin{array}{c}\text { Male } \\
(n=2,747)\end{array}$ & P-value \\
\hline \multicolumn{4}{|l|}{ Recipient } \\
\hline Age (years) & $54.0(43.0,61.0)$ & $57.0(49.0,63.0)$ & $<0.001$ \\
\hline Etiology (\%) & & & $<0.001$ \\
\hline Dilated & 38.7 & 36.4 & \\
\hline Ischemic & 22.8 & 45.0 & \\
\hline Others & 38.6 & 18.6 & \\
\hline Predicted heart mass $(g)$ & $126.8(118.1,138.2)$ & $176.0(164.5,189.2)$ & $<0.001$ \\
\hline Body mass index $\left(\mathrm{Kg} / \mathrm{m}^{2}\right)$ & $24.0(21.3,27.6)$ & $25.5(23.4,28.2)$ & $<0.001$ \\
\hline Diabetes (\%) & 12.1 & 23.3 & $<0.001$ \\
\hline Hypertension (\%) & 23.2 & 38.9 & $<0.001$ \\
\hline COPD (\%) & 6.1 & 12.2 & $<0.001$ \\
\hline Peripheral vascular disease (\%) & 2.6 & 7.8 & $<0.001$ \\
\hline Pretransplant malignancy (\%) & 8.5 & 4.1 & $<0.001$ \\
\hline GFR $\left(\mathrm{ml} / \mathrm{min} / 1.73 \mathrm{~m}^{2}\right)$ & $71.1(51.4,95.0)$ & $71.3(52.8,94.5)$ & 0.64 \\
\hline GFR $<45 \mathrm{~mL} / \mathrm{min} / 1.73 \mathrm{~m}^{2}$ & 17.6 & 15.0 & 0.08 \\
\hline CMV serology positive & 82.3 & 80.0 & 0.15 \\
\hline Bilirubin > 2 mg/dL & 15.3 & 18.9 & 0.02 \\
\hline Pulmonary vascular resistance (WU) & $2.0(1.3,2.9)$ & $2.0(1.3,2.8)$ & 0.42 \\
\hline Pre-transplant cardiac surgery (\%) & 25.3 & 29.2 & 0.03 \\
\hline Pre-transplant infection (\%) & 10.4 & 14.8 & 0.001 \\
\hline Pre-transplant mechanical ventilation (\%) & 15.5 & 14.4 & 0.44 \\
\hline Pre-transplant circulatory support (\%) & & & 0.002 \\
\hline None & 71.1 & 65.6 & \\
\hline IABP & 11.1 & 13.0 & \\
\hline ECMO & 8.1 & 7.3 & \\
\hline VAD & 9.7 & 14.1 & \\
\hline Recipient location (\%) & & & 0.08 \\
\hline Home & 56.0 & 52.5 & \\
\hline Hospital ward & 11.4 & 10.7 & \\
\hline Intensive care unit & 32.6 & 36.8 & \\
\hline \multicolumn{4}{|l|}{ Surgical procedure } \\
\hline Urgent transplant (\%) & 33.8 & 37.9 & 0.03 \\
\hline Cold ischemic time (min) & $210.0(153.3,240.0)$ & $205.0(155.0,245.0)$ & 0.94 \\
\hline Surgical technique (bicaval) (\%) & 61.0 & 64.3 & 0.08 \\
\hline Transplant era & & & 0.34 \\
\hline 2005-2009 & 31.4 & 33.7 & \\
\hline 2010-2014 & 30.1 & 30.3 & \\
\hline 2015-2019 & 38.4 & 36.0 & \\
\hline \multicolumn{4}{|l|}{ Donor } \\
\hline Age (years) & $45.0(34.0,53.0)$ & $44.0(32.0,52.0)$ & 0.11 \\
\hline Gender (female) & 57.3 & 28.7 & $<0.001$ \\
\hline Predicted heart mass (g) & $139.3(129.0,152.0)$ & $184.0(169.5,199.0)$ & $<0.001$ \\
\hline Body mass index $\left(\mathrm{Kg} / \mathrm{m}^{2}\right)$ & $24.4(22.5,26.7)$ & $26.0(24.0,28.4)$ & $<0.001$ \\
\hline CMV serology positive & 74.4 & 72.3 & 0.25 \\
\hline Cause of death (\%) & & & 0.02 \\
\hline Trauma & 24.2 & 29.0 & \\
\hline CVD & 49.3 & 46.7 & \\
\hline Other & 26.6 & 24.3 & \\
\hline \multicolumn{4}{|l|}{ Donor/recipient interaction } \\
\hline Donor/recipient gender mismatch (\%) & 42.7 & 28.7 & $<0.001$ \\
\hline
\end{tabular}




\begin{tabular}{|c|c|c|c|}
\hline & $\begin{array}{l}\text { Female } \\
(n=869)\end{array}$ & $\begin{array}{c}\text { Male } \\
(n=2,747)\end{array}$ & P-value \\
\hline Donor/recipient predicted heart mass ratio & $1.09(1.00,1.12)$ & $1.03(0.96,1.13)$ & $<0.001$ \\
\hline Donor/recipient CMV serology mismatch (\%) & 34.9 & 36.2 & 0.81 \\
\hline Donor/recipient BMI ratio & $1.00(0.89,1.16)$ & $1.01(0.91,1.14)$ & 0.31 \\
\hline
\end{tabular}

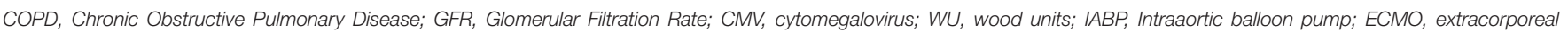
membrane oxygenator; VAD, ventricular assist device; CVD, cerebrovascular disease.

Although women received grafts from female donors who had a lower body mass index and predicted heart mass more often, donor/recipient sex mismatch was more frequent. Consequently, donor/recipient predicted heart mass ratio was higher.

Median follow-up was 1.01 years (interquartile range 0.711.01). Results of the univariate and multivariate Cox regression analysis are summarized in Table 2. Variables related to impaired survival included recipient age, higher body mass index, diabetes mellitus, bilirubin of $>2 \mathrm{mg} / \mathrm{dl}$, pre-HT infection, previous cardiac surgery, need for mechanical ventilation at the moment of HT, mechanical circulatory support at the time of HT, recipient location in the Intensive Care Unit, urgent transplant, cold ischemic time, female donor and donor/recipient sex mismatch, and donor/recipient body mass index ratio. Higher glomerular filtration rate, bicaval surgical technique, and HT in the recent period (2015-2019) were related to a better outcome. After multivariate analysis, body mass index and diabetes of the recipient lost statistical significance as did any type of mechanical circulatory support at the time of HT, recipient location at the time of HT, urgent status, female donor, and donor-recipient body mass index.

In the final model, variables independently related to reduced survival were recipient age, history of previous cardiac surgery, bilirubin of $>2 \mathrm{mg} / \mathrm{dl}$, pre-HT infection, need for mechanical ventilation at the moment of HT, cold ischemic time, and donor/recipient sex mismatch. Higher glomerular filtration rate, bicaval surgical technique, and HT in the recent period (20152019) were independently associated with a better prognosis.

Women and men had a similar 1-year survival (women 76.4 vs. $78.6 \%$ men $p=0.34$ ) by adjusted Kaplan-Meier analysis (Figure 1). We did not find any differences in the cause of death between men and women (Figure 2).

We did not find any interaction between sex and variables independently related to survival in the multivariate analysis (Table 3).

\section{DISCUSSION}

Advanced heart failure affects $1-10 \%$ of the overall HF population and implies a severe decline in patients' quality of life and survival. The Heart Failure Association of the European Society of Cardiology has recently updated diagnostic criteria. It focuses on patient referral to advanced HF centers and a proper transition of patients to palliative care (10). Although there are interesting HF registries to gather information about HF patients' clinical parameters and characteristics and their therapies, the advanced heart failure population is somehow challenging to study and scarcely described in the literature. Gender differences in HF patients have been previously described, but their clinical implications remain unclear. A better knowledge of the sexrelated differences appears as a potential field of improvement in the diagnosis, treatment, and likely prognosis of HF patients. The more significant publications addressing sex differences in advanced HF patients (waiting-list, HT, and VAD) are summarized in Table 4.

Previous studies with a small sample of patients showed a worse survival rate for women on the waiting list for HT (19). Several analyses of the Scientific Registry of Transplant Recipients of the United States of America have assessed the same topic. Hsich et al. in 2014 analyzed sex differences in patients listed for HT in 10 years (2000-2010) stratified by severity of illness (1A, high risk; $1 \mathrm{~B}$, intermediate risk; and 2, low-risk ambulatory patients) and adjusted by baseline characteristics. Women accounted for $25 \%$ of the study population, and they had a higher mortality rate than men in urgent status (1A) but a lower mortality rate than men in an elective ambulatory setting (status 2). No differences were observed in the intermediate-risk status 1B (11). Women were younger and had a non-ischemic cardiomyopathy more often, and men had a worse cardiovascular risk profile, and IHD was the leading cause for HF. The same authors tried to confirm these sex differences in a more recent period (2004-2015) and attempted to identify factors associated with waiting-list mortality and transplantation timing. Although similar differences in mortality were observed between 2004 and 2008 (higher mortality in woman in status $1 \mathrm{~A}$ and $1 \mathrm{~B}$ and lower in status 2), in the most recent years, some of them were solved, and women had a similar survival in urgent status $(1 \mathrm{~A})$ and elective status (2). They also identified many sex interactions for death and HT that varied with prioritization on the waiting list that should be addressed as a new field to understand these differences between men and women (12). Improvements in the risk of death or deterioration in women waiting for HT have also been observed in other studies (20).

There is also available information about sex-related differences in VAD therapy. As expected, baseline characteristics and underlying comorbidities and etiologies differed between men and women as it has been described for studies of patients on the HT waiting list. An analysis of the European Registry for Patients with Mechanical Circulatory Support showed that 
TABLE 2 | Uni- and multivariate Cox regression analysis of 1-y survival.

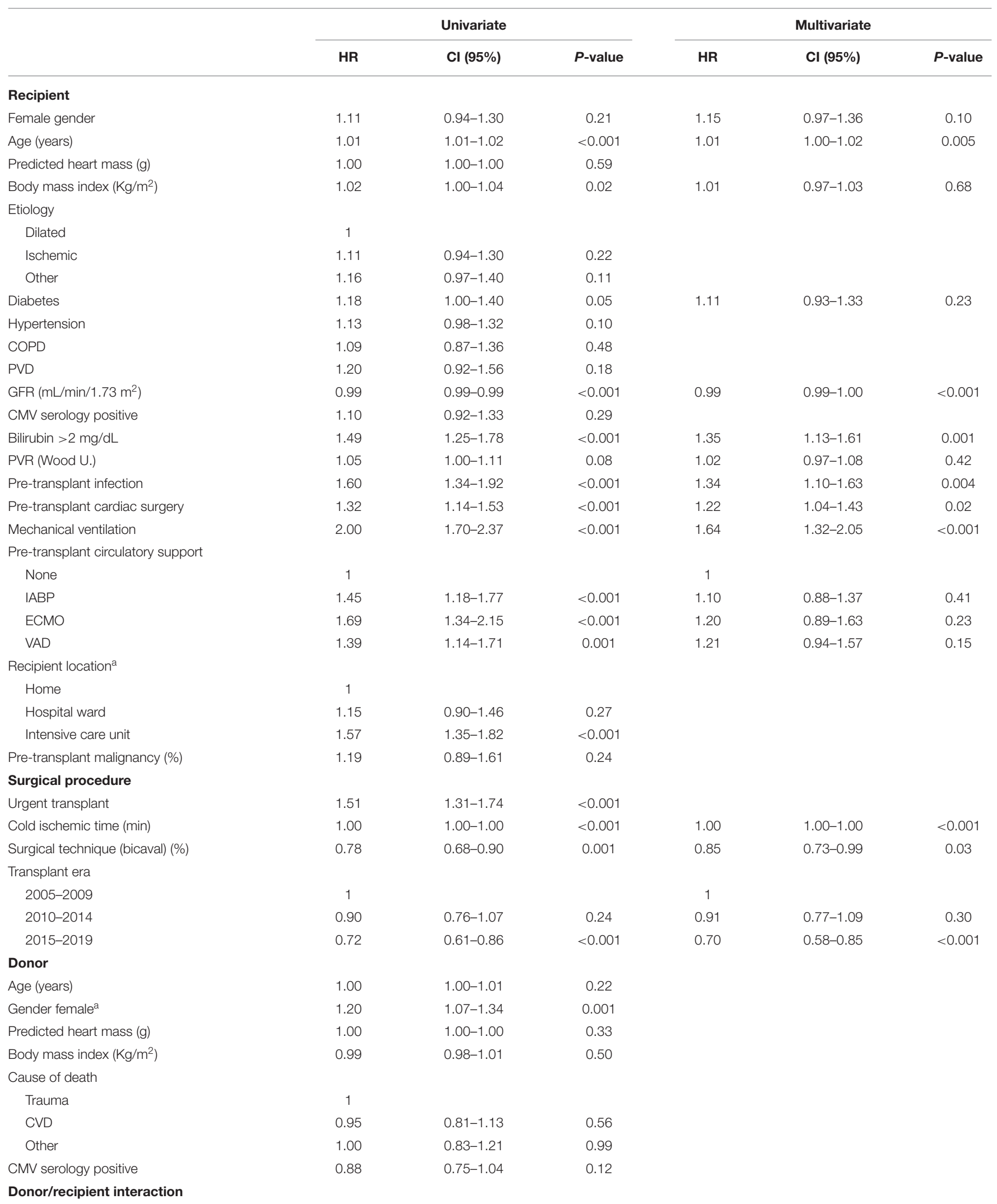




\begin{tabular}{|c|c|c|c|c|c|c|}
\hline & \multicolumn{3}{|c|}{ Univariate } & \multicolumn{3}{|c|}{ Multivariate } \\
\hline \multicolumn{7}{|l|}{ Recipient/Donor CMV mismatch } \\
\hline No & 1 & & & & & \\
\hline Donor (-)/recipient (+) & 1.14 & $0.96-1.37$ & 0.14 & & & \\
\hline Donor/recipient predicted heart mass ratio & 0.92 & $0.55-1.54$ & 0.75 & & & \\
\hline Donor/recipient body mass index ratio & 0.65 & $0.45-0.95$ & 0.02 & 0.80 & $0.50-1.28$ & 0.35 \\
\hline
\end{tabular}

HR, Hazard ratio; Cl, Confidence interval; COPD, Chronic obstructive pulmonary disease; CVD, cerebrovascular disease; ECMO, extracorporeal membrane oxygenator; GFR, glomerular filtration rate; IABP, intra-aortic balloon pump; PVD, peripheral vascular disease; PVR, pulmonary vascular resistance; VAD, ventricular assist device.

aUrgent transplant, recipient location, and donor sex were not included in the multivariate model due to collinearity with Pre-transplant Circulatory Support and recipient and donor sex.

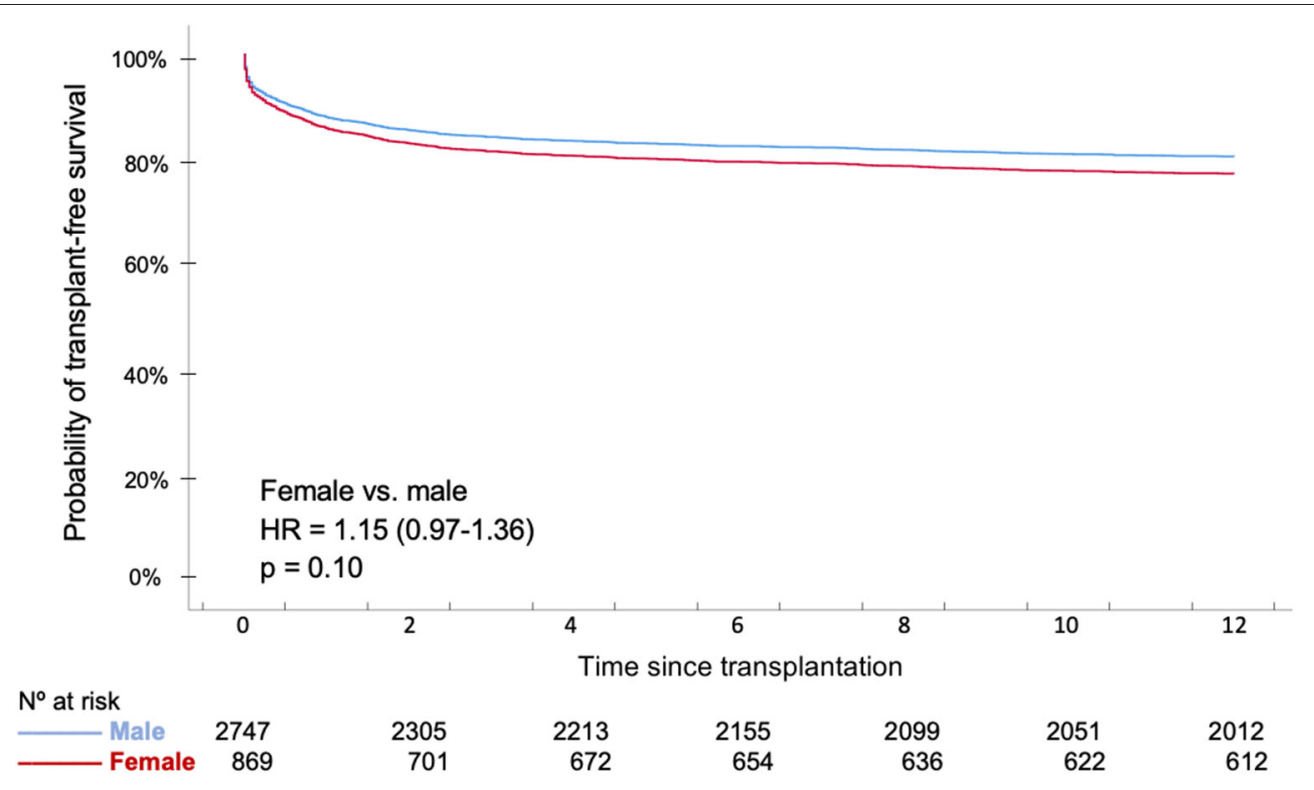

FIGURE 1 | Adjusted 1-year survival curves according to recipient sex.

only $15 \%$ of patients receiving a VAD were women. HT rates were similar for men and women. However, women were at a more advanced stage at the moment of implantation, presented a higher rate of significant bleeding, arrhythmias, and right ventricular failure, and had a worse prognosis than men (13). Two studies in the United States of America also showed a lower use of VAD in women, although slightly higher than in the European Registry (21-23\%). This higher percentage of women undergoing a VAD implantation might be explained by the inclusion of patients listed in a more recent time-lapse. Increasing use of VAD therapy in women throughout the observation period is described. Both American registries represent conflicting results on survival. The former is focused on in-hospital survival and showed similar survival for men and women (15). The latter evaluated more extended follow-up periods and described lower HT rates and a lower survival in women (14). In both registries, women presented with a more severe HF, but a similar adverse event rate. Those differences in outcomes may reflect different follow-up times and, thus, different rates of adverse events in men and women after perioperative period.

Several factors might play a role in sex-related differences in HT outcomes: the higher frequency of anti-HLA antibodies detection in women, differences in predicted heart mass as a critical factor in donor-recipient matching, and variability in clinical presentation men and women $(21,22)$. The New Heart study was the first one to address this topic. They found a similar survival for HT in women, who represented $28 \%$ of the analyzed population. Conversely, women were younger and developed graft rejection and needed hospitalization more often than men (16). An analysis of the International Society of Heart and Lung Transplantation Registry, in which $23.7 \%$ of included patients were women, also showed similar survival rates after adjusting by recipient and donor risk scores but suggested a higher mortality 


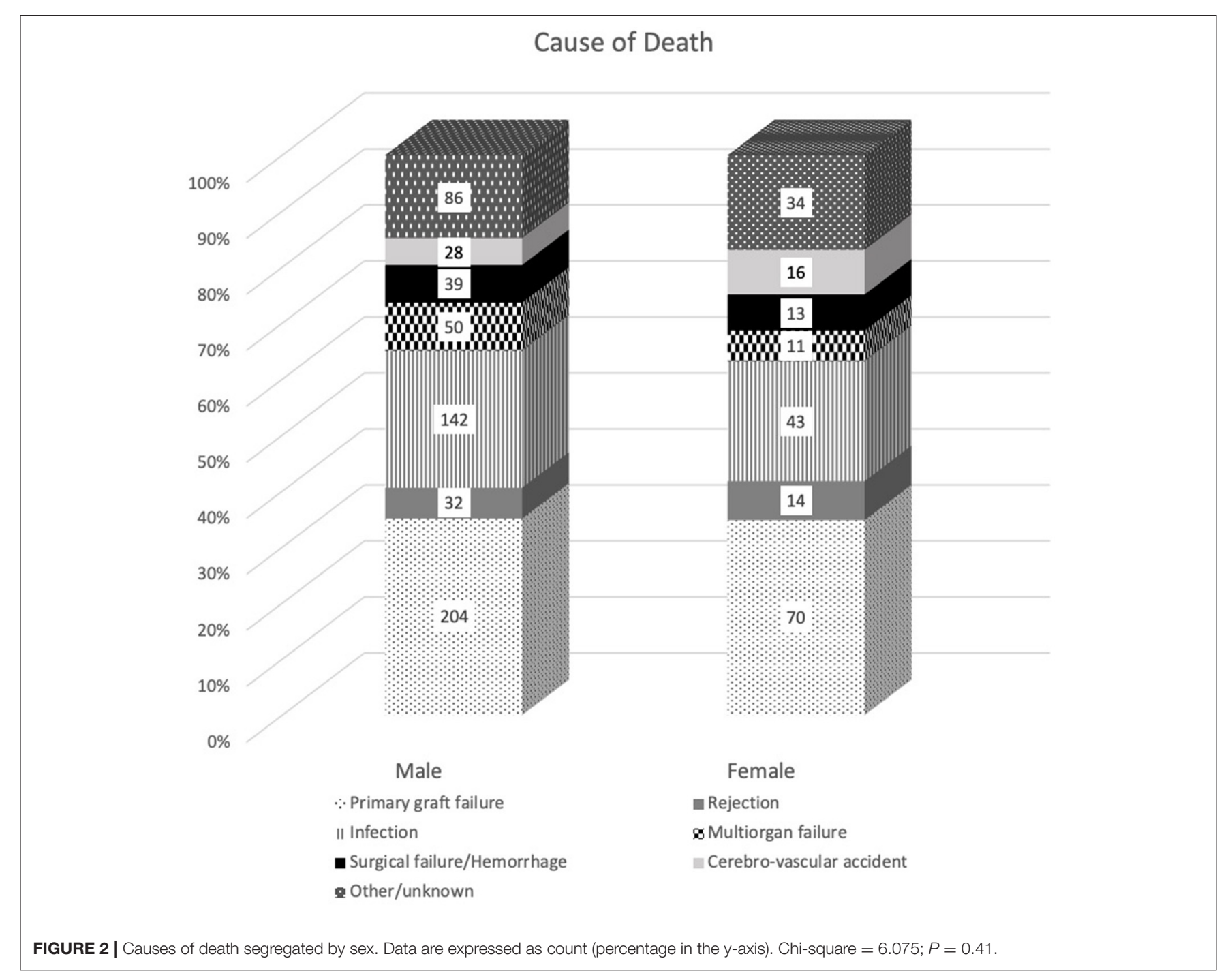

TABLE 3 | Analysis of interactions between recipient gender and significant variables in multivariate analysis.

\begin{tabular}{|c|c|c|c|c|c|c|}
\hline \multirow[t]{2}{*}{ Variable } & \multicolumn{3}{|c|}{ Recipient female gender } & \multicolumn{3}{|c|}{$\begin{array}{c}\text { Interaction } \\
\text { recipient sex * variable }\end{array}$} \\
\hline & HR & Cl (95\%) & $P$-value & HR & $\mathrm{Cl}(95 \%)$ & $P$-value \\
\hline Recipient age & 0.83 & $0.36-1.90$ & 0.66 & 1.01 & $0.99-1.02$ & 0.46 \\
\hline GFR (mL/min/1.73 m²) & 1.01 & $0.64-1.60$ & 0.95 & 1.00 & $0.99-1.01$ & 0.64 \\
\hline Bilirubin > 2 mg/dL & 1.08 & $0.89-1.30$ & 0.43 & 1.21 & $0.81-1.79$ & 0.35 \\
\hline Pre-transplant cardiac surgery & 1.08 & $0.88-1.31$ & 0.47 & 1.14 & $0.81-1.61$ & 0.46 \\
\hline Mechanical ventilation & 1.11 & $0.92-1.34$ & 0.30 & 1.06 & $0.73-1.54$ & 0.76 \\
\hline Bicaval surgical technique & 1.22 & $0.95-1.55$ & 0.12 & 0.87 & $0.62-1.20$ & 0.39 \\
\hline Cold ischemic time & 0.81 & $0.46-1.44$ & 0.47 & 1.00 & $1.00-1.00$ & 0.24 \\
\hline Transplant era & 1.04 & $0.79-1.37$ & 0.76 & & & \\
\hline
\end{tabular}

GFR, glomerular filtration rate. 
TABLE 4 | Summary of recent publications addressing gender differences in patients on the waiting for a heart transplant, receiving a long term ventricular assist device, or heart transplant recipients.

\begin{tabular}{|c|c|c|c|c|}
\hline Publication & Population & Period & Analysis & Conclusions \\
\hline Hsich et al. (11) & $\begin{array}{l}28852 \text { PWL } \\
24 \% \text { women } \\
\text { (SRTR) }\end{array}$ & 2000-2010 & $\begin{array}{l}\text { Propensity Score } \\
\text { Long term survival }\end{array}$ & $\begin{array}{l}\text { Women higher risk in urgent status } \\
\text { Similar results in intermediate status in men and women } \\
\text { Men higher risk in elective status }\end{array}$ \\
\hline Hsich et al. (12) & $\begin{array}{l}33069 \text { PWL } \\
25 \% \text { women } \\
\text { (SRTR) }\end{array}$ & 2004-2015 & $\begin{array}{l}3 \text { year survival } \\
\text { Random survival forest }\end{array}$ & $\begin{array}{l}\text { Higher risk in urgent and intermediate status in women, } \\
\text { similar in recent period } \\
\text { Higher risk in elective status in men } \\
\text { Multiple interactions between sex in different status }\end{array}$ \\
\hline Magnussen et al. (13) & $\begin{array}{l}966 \text { VAD }(75 \% \text { BTT) } \\
15 \% \text { women } \\
\text { (EUROMACS) }\end{array}$ & 2011-2014 & 1-2-year survival & $\begin{array}{l}\text { Similar HT rates } \\
\text { Women worse survival } \\
\text { Women sicker at implant } \\
\text { Women higher major bleeding, arrhythmias, and RV failure }\end{array}$ \\
\hline DeFilippis et al. (14) & $\begin{array}{l}13305 \text { VAD } \\
20.8 \% \text { women } \\
\text { (UNOS) }\end{array}$ & 2008-2018 & $\begin{array}{l}\text { Propensity Score } \\
\text { 1-2-year survival }\end{array}$ & $\begin{array}{l}\text { Increase in VAD use among decade (lower in women) } \\
\text { Women sicker at implant, similar complications } \\
\text { Women lower HT rate and survival }\end{array}$ \\
\hline Ahmed et al. (15) & $\begin{array}{l}3511 \text { VAD } \\
23.3 \% \text { women } \\
\text { (NIS) }\end{array}$ & 2009-2014 & $\begin{array}{l}\text { Propensity Score } \\
\text { In hospital survival }\end{array}$ & $\begin{array}{l}\text { Similar survival } \\
\text { Similar complications } \\
\text { VAD in females have doubled lately }\end{array}$ \\
\hline Hickey et al. (16) & $\begin{array}{l}345 \text { HT } \\
28 \% \text { women } \\
\text { NEW HEART study }\end{array}$ & 2011-2015 & 1-year survival & $\begin{array}{l}\text { Similar survival } \\
\text { Women younger } \\
\text { Women more rejection episodes and hospitalizations }\end{array}$ \\
\hline Moayedi et al. (17) & $\begin{array}{l}34198 \mathrm{HT} \\
23.7 \% \text { women } \\
\text { (ISHLTR) }\end{array}$ & 2004-2014 & $\begin{array}{l}\text { Propensity Score } \\
\text { Adjusted IMPACT / DRI } \\
\text { Long-term survival }\end{array}$ & $\begin{array}{l}\text { Similar survival } \\
\text { Lowest survival in undersized donors } \\
\text { Women higher mortality in regular sized donors }\end{array}$ \\
\hline García-Cosío et al. (18) & $\begin{array}{l}6740 \mathrm{HT} \\
20.6 \% \text { women } \\
\text { (SHTR) }\end{array}$ & 1997-2017 & $\begin{array}{l}\text { Temporal trends } \\
\text { Transplant rate pmh } \\
\text { Long term survival }\end{array}$ & $\begin{array}{l}\text { Similar survival } \\
\text { Similar HT pmh in women among } 25 \text { years (lower in men) } \\
\text { Women died due to rejection and primary graft failure } \\
\text { Men died due to malignancies }\end{array}$ \\
\hline Current series & $\begin{array}{l}3616 \text { HT } \\
24 \% \text { women } \\
\text { (SHTR) }\end{array}$ & 2005-2019 & 1-year survival & Similar survival \\
\hline
\end{tabular}

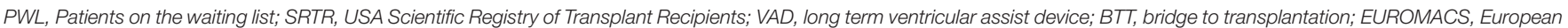

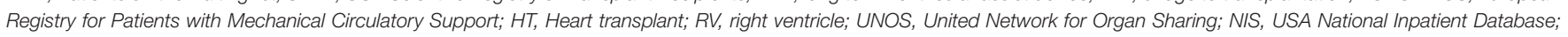

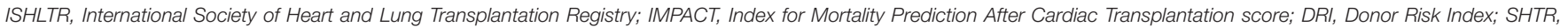
Spanish Heart Transplant Registry; Pmh, per million habitants.

rate to women who received a graft of a regular-sized donor (17). Our previous work analyzing the Spanish Heart Transplant Registry results over the last 25 years showed a similar survival and similar HT rate in women per million habitants. Causes of death differed between men, mainly due to neoplastic diseases, and women, mainly due to primary graft failure and rejection (18). All the described studies show a comparable pattern of baseline characteristics and underlying heart disease.

Our study aims to describe sex-related differences in 1-year outcomes after an HT in a contemporary cohort. Given that previous studies showed sex-related differences in higher-risk recipients, we sought to analyze 1-year HT results as they may be affected considerably by perioperative factors like the patient's clinical situation on the waiting list or the etiology of HF.

We did not find differences in the recipient's location (outpatient or hospitalized) at the time of HT. The need for circulatory support at the moment of HT was more frequent in men (mainly VAD), but it was not associated with different outcomes. VADs were used in a low percentage of HT candidates in our cohort. Given that VAD therapy may have different results in men and women, we cannot extrapolate our results to other populations with a higher VAD use. Urgent HT was more frequent in men, but it was not associated with higher mortality after multivariate analysis. We cannot determine whether this difference is influenced by a higher delisting rate of women due to clinical deterioration before HT or different use of therapies that determine urgent status in our country (i.e., intra-aortic balloon pump until 2015, extracorporeal membrane oxygenator, or VAD).

To conclude, despite sex-related differences in the clinical profile and the donor-recipient matching, 1-year outcomes are comparable. We did not find differences in the cause of death, and we did not find any interactions between sex and factors significantly associated with differences in survival.

\section{LIMITATIONS}

Our analysis of 1-year outcomes after HT has some limitations that must be acknowledged. The main limitation is the lack of information about patients included on the waiting list for HT 
since the patient's follow-up begins at HT. Thus, we do not have any data about those patients who are included on the waiting list and are delisted or died before HT. Another limitation is the low rate of VAD implantation in our cohort that prevents us from extrapolating these results to other populations. Furthermore, the retrospective nature of a registry analysis also constitutes a significant limitation.

\section{CONCLUSION}

Women are under-represented in the waiting list for an HT or a VAD. Although clinical profile and HF etiology differ between men and women, overall survival and complications are similar. It is desirable to study sex-related differences to understand if we should adjust clinical protocols in advanced HF patients by sex.

\section{DATA AVAILABILITY STATEMENT}

The raw data supporting the conclusions of this article will be made available by the authors, without undue reservation.

\section{ETHICS STATEMENT}

Ethical review and approval was not required for the study on human participants in accordance with the local legislation and institutional requirements. The patients/participants provided their written informed consent to participate in this study.

\section{REFERENCES}

1. Tamargo J, Rosano G, Walther T, Duarte J, Niessner A, Kaski JC, et al. Gender differences in the effects of cardiovascular drugs. Eur Hear J. (2017) 3:163-82. doi: 10.1093/ehjcvp/pvw042

2. Crespo Leiro MG, Paniagua Martín MJ. Heart failure. Are women different? Rev Esp Cardiol. (2006) 59:725-35. doi: 10.1016/S1885-5857(07)60031-0

3. Dunlay SM, Roger VL. Gender differences in the pathophysiology, clinical presentation, and outcomes of ischemic heart failure. Curr Heart Fail Rep. (2012) 9:267-76. doi: 10.1007/s11897-012-0107-7

4. Gómez-Martínez L, Orozco-Beltrán D, Quesada JA, Bertomeu-González V, Gil-Guillén VF, López-Pineda A, et al. Trends in premature mortality due to heart failure by autonomous community in Spain: 1999 to 2013. Rev Esp Cardiol. (2018) 71:531-7. doi: 10.1016/j.rec.2017.09.026

5. Aimo A, Vergaro G, Castiglione V, Barison A, Pasanisi E, Petersen C, et al. Effect of sex on reverse remodeling in chronic systolic heart failure. JACC Hear Fail. (2017) 5:735-42. doi: 10.1016/j.jchf.2017.07.011

6. Martinez-Selles M, Almenar L, Paniagua-Martin MJ, Segovia J, Delgado JF, Arizón JM, et al. Donor/recipient sex mismatch and survival after heart transplantation: only an issue in male recipients? an analysis of the Spanish Heart Transplantation Registry. Transpl Int. (2015) 28:30513. doi: $10.1111 /$ tri. 12488

7. Khush KK, Kubo JT, Desai M. Influence of donor and recipient sex mismatch on heart transplant outcomes: analysis of the International Society for Heart and Lung Transplantation Registry. J Hear Lung Transplant. (2012) 31:45966. doi: 10.1016/j.healun.2012.02.005

8. Kaczmarek I, Meiser B, Beiras-Fernandez A, Guethoff S, Überfuhr P, Angele M, et al. Gender does matter: gender-specific outcome analysis of 67,855 heart transplants. Thorac Cardiovasc Surg. (2013) 61:2936. doi: 10.1055/s-0032-1331467

\section{AUTHOR CONTRIBUTIONS}

MG-C, JD, and FG-V have contributed to the conception and design of the work. MG-C and FG-V have contributed to the analysis and interpretation of the work's data and drafting. BM, RL-V, EB-C, MG, MM-S, JM, DR, JG-C, SM, FP-V, GR, AP, LdlF, and IG have contributed in revising the article critically. All authors contributed to the article and approved the submitted version.

\section{FUNDING}

This investigation was funded by Centro de Investigación en Red de Enfermedades Cardiovasculares (CIBERCV), Instituto de Salud Carlos III, and Spanish Ministry of Economy and Competitiveness.

\section{ACKNOWLEDGMENTS}

We would like to acknowledge all people involved in the conception, development, and maintenance of the Spanish Heart Transplantation Registry.

\section{SUPPLEMENTARY MATERIAL}

The Supplementary Material for this article can be found online at: https://www.frontiersin.org/articles/10.3389/fcvm. 2021.630113/full\#supplementary-material

9. González-Vílchez F, Gómez-Bueno M, Almenar-Bonet L, Crespo-Leiro MG, Arizón del Prado JM, Delgado-Jiménez J, et al. Registro Español de Trasplante Cardiaco. XXVIII Informe Oficial de la Sección de Insuficiencia Cardiaca de la Sociedad Española de Cardiología (1984-2016). Rev Española Cardiol. (2017) 70:1098-109. doi: 10.1016/j.recesp.2017.07.032

10. Crespo-Leiro MG, Metra M, Lund LH, Milicic D, Costanzo MR, Filippatos G, et al. Advanced heart failure: a position statement of the Heart Failure Association of the European Society of Cardiology. Eur J Heart Fail. (2018) 20:1505-35. doi: 10.1002/ejhf.1236

11. Hsich EM, Starling RC, Blackstone EH, Singh TP, Young JB, Gorodeski $\mathrm{EZ}$, et al. Does the UNOS heart transplant allocation system favor men over women? JACC Hear Fail. (2014) 2:347-55. doi: 10.1016/j.jchf.2014. 03.008

12. Hsich EM, Blackstone EH, Thuita L, McNamara DM, Rogers JG, Ishwaran $\mathrm{H}$, et al. Sex differences in mortality based on united network for organ sharing status while awaiting heart transplantation. Circ Hear Fail. (2017) 10:e03635. doi: 10.1161/CIRCHEARTFAILURE.116.003635

13. Magnussen C, Bernhardt AM, Ojeda FM, Wagner FM, Gummert J, de By TMMH, et al. Gender differences and outcomes in left ventricular assist device support: the European Registry for Patients with Mechanical Circulatory Support. J Hear Lung Transplant. (2018) 37:61-70. doi: 10.1016/j.healun.2017.06.016

14. DeFilippis EM, Truby LK, Garan AR, Givens RC, Takeda K, Takayama $\mathrm{H}$, et al. Sex-related differences in use and outcomes of left ventricular assist devices as bridge to transplantation. JACC Hear Fail. (2019) 7:2507. doi: 10.1016/j.jchf.2019.01.008

15. Ahmed A, Adegbala O, Akintoye E, Inampudi C, Ajam M, Yassin AS, et al. Gender differences in outcomes after implantation of left ventricular assist devices. Ann Thorac Surg. (2020) 109:780-6. doi: 10.1016/j.athoracsur.2019.07.032 
16. Hickey KT, Doering LV, Chen B, Carter EV, Sciacca RR, Pickham D, et al. Clinical and gender differences in heart transplant recipients in the NEW HEART study. Eur J Cardiovasc Nurs. (2017) 16:222-9. doi: 10.1177/14745151166 51178

17. Moayedi Y, Fan CPS, Cherikh WS, Stehlik J, Teuteberg JJ, Ross HJ, et al. Survival outcomes after heart transplantation: does recipient sex matter? Circ Heart Fail. (2019) 12:e006218. doi: 10.1161/CIRCHEARTFAILURE.119. 006218

18. García-Cosío MD, González-Vilchez F, López-Vilella R, Barge-Caballero E, Gómez-Bueno M, Martínez-Selles $\mathrm{M}$, et al. Gender differences in heart transplantation: Twenty-five year trends in the nationwide Spanish heart transplant registry. Clin Transplant. (2020) 2020:e14096. doi: 10.1111/ctr. 14096

19. Weidner G, Zahn D, Mendell NR, Smits JMA, Deng MC, Zittermann A, et al. Patients' sex and emotional support as predictors of death and clinical deterioration in the waiting for a new heart study: results from the 1-year follow-up. Prog Transplant. (2011) 21:106-14. doi: 10.7182/prtr.21.2.j779w1q6k61k $0 \mathrm{jk} 4$

20. Morris AA, Cole RT, Laskar SR, Kalogeropoulos A, Vega JD, Smith A, et al. Improved outcomes for women on the heart transplant wait list in the modern era. J Card Fail. (2015) 21:555-60. doi: 10.1016/j.cardfail.2015. 03.009

21. Kransdorf EP, Kittleson MM, Benck LR, Patel JK, Chung JS, Esmailian F, et al. Predicted heart mass is the optimal metric for size match in heart transplantation. J Hear Lung Transplant. (2019) 38:156-65. doi: 10.1016/j.healun.2018.09.017

22. Klein SL, Flanagan KL. Sex differences in immune responses. Nat Rev Immunol. (2016) 16:626-38. doi: 10.1038/nri.2016.90

Conflict of Interest: The authors declare that the research was conducted in the absence of any commercial or financial relationships that could be construed as a potential conflict of interest.

Copyright (C) 2021 García-Cosío, González-Vilchez, López-Vilella, Barge-Caballero, Gómez Bueno, Martínez-Selles, María Arizón, Rangel Sousa, González-Costello, Mirabet, Pérez-Villa, Molina, Rábago, Portolés Ocampo, de la Fuente Galán, Garrido and Delgado. This is an open-access article distributed under the terms of the Creative Commons Attribution License (CC BY). The use, distribution or reproduction in other forums is permitted, provided the original author(s) and the copyright owner(s) are credited and that the original publication in this journal is cited, in accordance with accepted academic practice. No use, distribution or reproduction is permitted which does not comply with these terms. 